\title{
69. Thirty Years of Distance Education: Personal Reflections
}

\author{
Terralyn McKee \\ Athabasca University, Canada
}

\begin{abstract}
This paper reflects on the evolving experience of modern distance education (DE) as a field of practice for professionals and as a medium for student access to education and training. The writer's 30 years in the field, as both teacher and student, has coincided with the five-stage evolution of DE delivery defined by Taylor (1995-2010). The author considers the perceived identity crisis and diverse theoretical frameworks of the field since the 1980s as well as the need for new levels of change management to enable the tools, technologies, and emerging systems of $\mathrm{DE}$ in order to create the flexibility, responsiveness, and networking that students require and that teachers need to learn.
\end{abstract}

Keywords: Distance education delivery; correspondence; multimedia; telelearning; flexible learning; intelligent flexible learning

\section{Introduction}

I have started this paper numerous times only to walk away in frustration. I had wished to record my personal journey through 30 years of distance education (DE) and its technologies for some time and thought the task would be easy. Ultimately, it has been like trying to hit a moving target. The field appears to have a constant identity crisis, defined by a developmental deluge of pedagogies and technologies depending on the favoured course delivery methods of the day. Moore (1985) summed up this situation in stating that most published DE research is descriptive and not generalisable, is only marginally based in theory, and is deficient in disciplined research under controlled conditions.

The rate of technology's development and integration in education since then has added to this confusion. Advances in the digital architecture of the Internet and Worldwide Web have presented a dazzling array of new possibilities for professional and social relationships. In the evolving dissonance of mediated environments, I have struggled to articulate my personal unease with the pedagogical applications of technology during my 30 years of distributed teaching and 
learning. I have experienced education face-to-face, by postal correspondence, by correspondence with telephone support, by correspondence augmented with audio and then videotape, broadcast, computer-mediated, blended in-class teaching and learning, and now by digital education on the Web. The constant deluge of data and technologies, combined with the pace at which learning environments continue to change, have left me more than confused as a student, and almost terrified as a teacher in my concern to keep up!

\section{Five Generations of Distance Learning}

DE technologies and practices have undergone radical transformations during the past 50 years and are considered by many to be the leading edge of academic opportunity for postsecondary institutions. Seeking a structure for my personal reflections, I finally found it in the analysis of the ongoing iterations of DE technologies by Taylor $(1995,2001)$. Taylor describes the evolution of technological innovation in DE in a way that mirrors my own DE experiences (Table 1). The transformation process I have been forced through has been volatile and evanescent. Having experienced all five of Taylor's evolutionary stages in one capacity or another, I will use his five generations of DE technology as an organisational guide for this paper.

Table 1

Generations of Distance Education (Taylor, 2001)

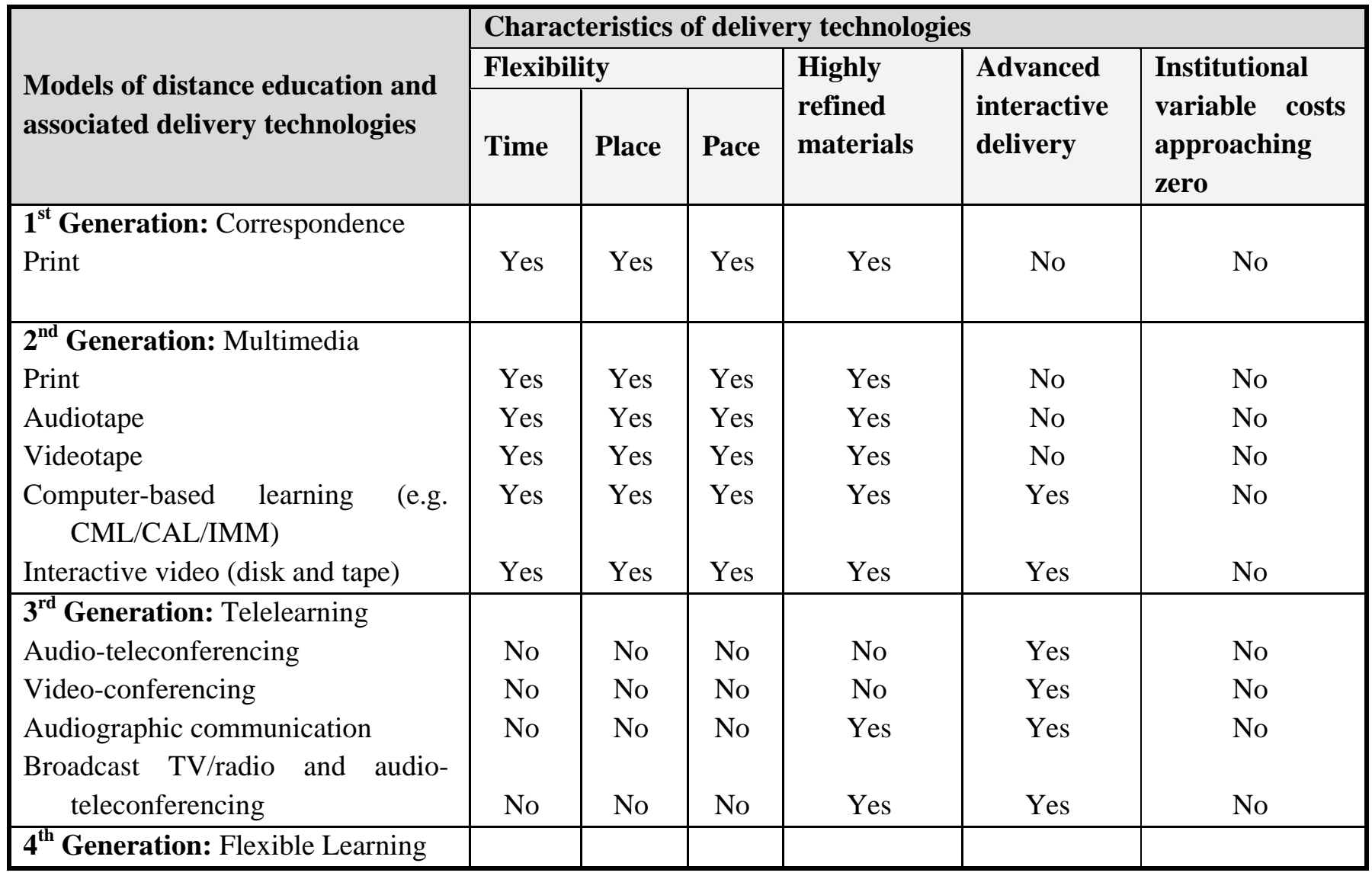




\begin{tabular}{|c|c|c|c|c|c|c|}
\hline $\begin{array}{l}\text { Interactive multimedia (IMM) } \\
\text { online } \\
\text { Internet-based access to WWW } \\
\text { resources } \\
\text { Computer-mediated communication }\end{array}$ & $\begin{array}{l}\text { Yes } \\
\text { Yes }\end{array}$ & $\begin{array}{l}\text { Yes } \\
\text { Yes }\end{array}$ & $\begin{array}{l}\text { Yes } \\
\text { Yes }\end{array}$ & $\begin{array}{l}\text { Yes } \\
\text { Yes }\end{array}$ & $\begin{array}{l}\text { Yes } \\
\text { Yes }\end{array}$ & $\begin{array}{l}\text { Yes } \\
\text { No }\end{array}$ \\
\hline $\begin{array}{l}5^{\text {th }} \text { Generation: } \\
\text { Intelligent Flexible Learning } \\
\text { Interactive multimedia (IMM) } \\
\text { online }\end{array}$ & Yes & Yes & Yes & Yes & Yes & Yes \\
\hline $\begin{array}{l}\text { Internet-based access to WWW } \\
\text { resources }\end{array}$ & Yes & Yes & Yes & Yes & Yes & Yes \\
\hline $\begin{array}{l}\text { Computer mediated } \\
\text { communication, using automated } \\
\text { response systems } \\
\text { Campus portal access to } \\
\text { institutional processes and resources }\end{array}$ & Yes & Yes & Yes & Yes & Yes & Yes \\
\hline
\end{tabular}

\section{Correspondence Education (First Generation)}

\section{Print.}

The experience of correspondence education is dependent upon the literacy skills of the learner and upon the course design expertise of the teacher and institution. My own experiences with correspondence education support the suggestion by Bourdeau and Bates (1996) and MorteraGutiérrez (2006) that the delivery method is less critical than the design and management process. I believe I have experienced the gamut of DE correspondence courses, from the exceptional to the poor, disorganised, and incoherent. The chief component in my assessments is the quality of dialogue that the materials have afforded me as a learner. Moore's theory of transactional distance (1997) explored how the DE dialogue, even conducted by remote participants, can provide an unique form of communication between teacher and student. Print materials have the capacity to provoke dialogue and to reduce the emotional and cognitive distance between these two participants.

In fact, Moore went as far as to describe the student's experience of print materials as "a form of learner-instructor dialogue because the learner (has) an internal or silent interaction with the person who in some distant place and time organized a set of ideas or information for transmission.” To describe the student's relationship with printed content as in any way an actual interaction might be interpreted as devaluing human interaction in education. A recent metaanalysis of online study, however, has indicated that learning is predicted more by the quality of Moore's "student-content interaction" than by "student-student" or even "student-instructor interaction" (Bernard et al., 2009). Indeed, the aspects of correspondence-type course delivery that I have appreciated the most, both as a student and a teacher, are the permanence and ease-ofuse of print materials, the relatively inexpensive construction process of learning packages, the 
limited technology knowledge required for interaction with the materials, and the ability to match the learning to my schedule and place of study. Experience tells me that the most effective correspondence courses adhere to prescribed design formats that are intuitive, sequential, complete, and organized, and that support both the learner and the content.

The disadvantage of the print-based method is the limited interaction possible with teachers and classmates. The ability to interact with the materials is also limited to the strength of the dialogue created by the materials and the teacher. It is hard to remain motivated by static content and to personalise or extend its learning opportunities. For a teacher, the process is equally difficult because of the partial assumptions that are possible about the students' prior knowledge and experience of the course content. In addition, the evaluation process for this type of learning can miss the richness and insight of the teacher-student relationship and may not accurately measure the true educational effects. Personally, I do not "test" well and have been frustrated by the summative approaches of many correspondence course evaluations. Summative evaluations left to the end of a course, the point of no return, miss the opportunity to identify and to deal with areas of misunderstanding regarding key concepts. This problem is especially serious when the course relies upon postal service alone,

Moore (1997) summarised this situation as follows: "It is the separation of learners and teachers that profoundly affects both teaching and learning. With separation there is a psychological and communications space to be crossed, a space of potential misunderstanding between the inputs of teacher and those of the learner."

\section{Mixed Media Delivery (Second Generation)}

\section{Print, audiotape, videotape, computer-based learning, interactive video (disk and tape).}

I tend to think of second-generation distance education as correspondence courses on steroids, good, bad, or downright ugly. The innovations with respect to audio/visual tools expanded learning opportunities in distance education by enriching the delivery options. The content could now sing and dance and offered new options for teacher-student interaction. The "tyranny of proximity,” as Taylor (1995) called it, was diminishing. As with any emerging new system, however, these tools have frequently been used to less than full effect.

- The Ugly: I once received a distance course about religious philosophy from a reputable university, in a set of 10 audio cassettes, a textbook, and a print syllabus. By the seventh hour of the audio cassettes, I felt desperate. They were taped during course lectures, the quality of the sound was awful, and the organisation of the materials followed the whim of the in-class discussion, which was never audible and in which questions were not reframed for the benefit of the distance learner. Overall, the impact of these aids in the course, for me, was negative and counter-productive. 
- The Good: In contrast, I had the pleasure of taking an education course for secondary school counseling, which was the epitome of instructional design. The course was conducted in the same institution as the ugly course, but with a different teacher. The materials arrived with several audiotapes produced by the professor in a quiet area, which supported key content areas, a videotape demonstrating effective counseling techniques, two textbooks, and an expertly produced learning guide, which prefaced the learning objectives, was sequential, informative, and graphically appealing, used frequent reinforcing self-quizzes, and provided optional activities for assignments. I remained highly motivated throughout this course because it catered to my preferred learning style and reduced transactional distance by providing a visceral connection to the materials and to the teacher.

\section{Telelearning (Third Generation)}

\section{Audio-teleconferencing, video-conferencing, audiographic communication, and broadcast TV/radio.}

Audio- and video-conferencing addressed transactional distance issues by adding the synchronous element to learning that only face-to-face education had afforded previously. Despite the awkwardness of the communication media (e.g., protocols for turn-taking and the ability to share thoughts), the capacity to transmit and participate through a technology that allowed synchronous sharing of voice, data, and graphic images was critical to my further commitment to distance learning. With all the benefits of the new technologies came the inevitable glitches and access issues as well as the endless learning curve required to keep pace with the new technologies. But the content now had the ability to sing and dance, and I was able to interact with it as a teacher as well as a student and to construct my experience in way that I found engaging and motivating. As an added bonus, the experience gave me the urge to understand how my Apple IIe worked and to find ways of making that information useful to my own students in the classroom.

Although I am not greatly in favour of direct education as a primary teaching model, I do have respect for the wide range of approaches it provides for knowledge and skills acquisition. I appreciate the information modeling and guided practice which provides as much repetition as the student needs to master information before moving on to higher-order thinking skills (Hunter, 1994). Without a solid foundation in the terminologies, processes, and conceptual frameworks of a topic, the higher-order issues are less meaningful. Computer-mediated direct instruction allows skill-and-drill processes that many teachers tire of after a few iterations, and it allows the individual student to monitor his or her own progress and to plan further iterations as needed. 


\section{Flexible Learning (Fourth Generation)}

\section{Interactive multimedia (IMM) online, Internet-based access to WWW resources, computer-mediated communication.}

If, as I described earlier, the second-generation mixed-media approach to DE is correspondence courses on steroids, the fourth generation takes things to a new level and begins to resemble the science-fiction film, The Matrix. Distance educators and designers are presented with completely new challenges - to understand and define innovative philosophy, epistemology, codes of ethics, aesthetics, politics, culture, and practice. In this respect, DE is living up to its reputation described by Christensen (1997) as a disruptive innovation - dynamic, radical, and unpredictable in terms of its evolution and use. Current DE is experiencing growing pains at the most basic levels and is prompting reflection across the educational field as a whole. The technologies are creating opportunities for students and educators to view educational processes, goals, definitions, and environments (face-to-face and distance) in exciting new lights and as ripe with possibility. Access to the Worldwide Web has forever changed how I learn as a student, grow as a professional, and teach in my classroom. One-size-fits-all education is giving way to customisation in content, learning styles, methodology, and practice. Information can be personalised to create knowledge that is unique and boundless through connection to the power of co-creation with peers. I enjoy the opportunity to connect with peers online to discuss course assignments and practical and theoretical applications of new information. Sharing and actually co-editing presentations synchronously has generated insights into learner-directed approaches, which are so valuable in the current global economy. I have sought actively to incorporate the approaches I have learned from DE in my face-to-face classes, capitalising on the best technological methods of both approaches.

The types of tools and technology that I have used in my personal journey through DE generations 1 to 4 are listed in Table 2. As may be apparent from this paper so far, however, the process for me has been less about technology per se and more about the process of integrating innovation into coherent teaching and learning practices.

Table 2

The Author's Journey with Different DE Tools and Technologies

\begin{tabular}{|l|l|}
\hline Text & $\begin{array}{l}\text { IRC (Internet relay chat - mIRC, ICQ, etc), Microsoft } \\
\text { Outlook (email), MSN Messenger, bulletin boards, } \\
\text { threaded discussion boards, Google Groups, wikis, } \\
\text { WebBoard, blogs }\end{array}$ \\
\hline Audio-conferencing & $\begin{array}{l}\text { Speakerphone, polycom, operator-assisted conferencing } \\
\text { (most reliable), Flash }\end{array}$ \\
\hline $\begin{array}{l}\text { Audio/video (i.e., all of the programs } \\
\text { listed under audio-conferencing, with } \\
\text { the added feature of visual engagement) }\end{array}$ & $\begin{array}{l}\text { GoTo Meeting, Desire2Learn, WebCT (too complicated), } \\
\text { Moodle (most intuitive), Powerpoint, SlideShare, Skype, } \\
\text { Flickr, YouTube }\end{array}$ \\
\hline
\end{tabular}




\section{Intelligent Flexible Learning (Fifth Generation)}

\section{Interactive multimedia (IMM) online, Internet-based access to WWW resources, computer-mediated communication, using automated response systems, campus portal access to institutional processes and resources.}

How is the fifth generation different from the fourth? Taylor (2001) identified it as a "derivation" that provides the fluidity, flexibility, and speed needed to drive the next iteration of educational technology in an age where knowledge and information are the chief currencies. The current iterations seem boundless, and Taylor (2010) now identifies three separate fifth-generation levels, involving various blended learning approaches. While the emerging innovations may be difficult to predict, the need driving them is not. The learner in the digital age (digital native) is immersed in a technological environment with little separation between formal learning, social networks, recreation, and employment. An emerging theory that addresses this learning construct is connectivism (Siemens, 2006), and it is a current driving force behind my personal philosophical orientation in DE. The traits exhibited by learners today, as demonstrated by Siemens in Figure 1 , most accurately depict my own processes and preferred styles, regardless of the educational media used online or in class.

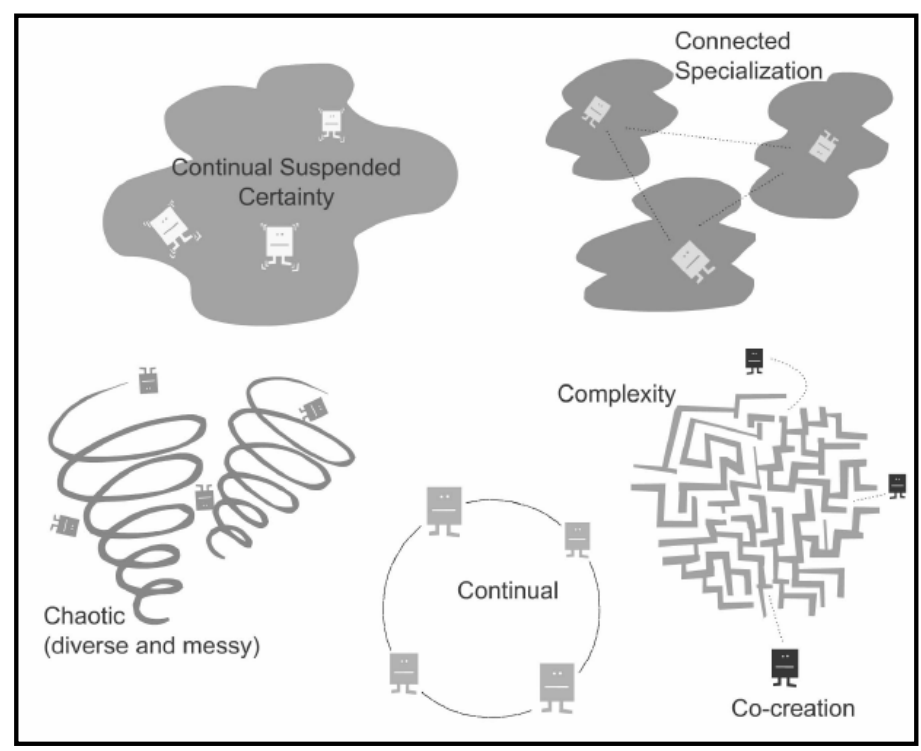

Figure 1. Traits of Learning Today (Siemens, 2006).

The boundary between online and in-class situations in the connectivist approach is more theoretical than actual, as blended approaches are rapidly becoming the norm. Taylor (2001) defined the fifth-generation type of $\mathrm{DE}$ as an "intelligent flexible learning model” seamlessly integrating all aspects of the educational system, including administration, enrolment, commerce, publishing, and distribution. The skill sets and knowledge requirements of future generations will 
look quite different from those required today. Meeting this challenge with appropriate systems, tools, and processes will be a daunting task given the current rate of technological change.

The DE system has struggled to make effective use of the early Web 1.0 methods. With the development of the new interactive Web, popularly known as Web 2.0 (O’Reilly, 2005), distance educators are attempting to capitalise on an even wider range of technologies, although my perception is that they have not yet glimpsed the full paradigm shift that is emerging in knowledge construction and management in this new technological environment. Web 2.0 methods have introduced interactive networking concepts that enliven educational activities with greater personalised meaning and socialised connectivity. Still, however, many educators resist collaborative learner-directed approaches that shift power and control away from the institutions and individuals and towards a more personally connected web of educational experience. On the cusp of a "Web 3.0 (r)evolution" (Agarwal, 2009), DE continues to flounder in this perplexing technological world without a consistent identity or commitment to its organisation and development.

\section{Conclusions}

In my ideal distance education delivery system, the process of change management in innovation is more important than tools, technologies, and systems. These change, evolve, and are often abandoned as the cycle of change folds back upon itself. My own ideal distance-based delivery system is changeable based on context and environment; flexible and responsive to the demands of the content, connections, and tools; connected in a vast ocean of academic and social networks, allowing construction of individual and shared ideologies and knowledge frameworks; and sufficiently intuitive to acknowledge my prior experiences and knowledge in building a system appropriate to my level of understanding, interest, and commitment. My personal journey through 30 years of this evolutionary process has left me dizzied by the pace of change, but ultimately optimistic for the generations to come. 


\section{References}

Agarwal, A. (2009). Web 3.0 concepts explained in plain English. Retrieved from http://www.labnol.org/Internet/web-3-concepts-explained/8908/

Bernard, R., Abrami, P., Wade, A., Borokhovski, E., Tamim, R., Surkes, M., \& Bethel, E. (2009). A meta-analysis of three interaction treatments in distance education. Review of Educational Research, 79(3), 1243-1289.

Bourdeau, J., \& Bates, A. (1996). Instructional design for distance learning. Journal of Science Education \& Technology, 5(4), 267-283.

Christensen, C. (2000). The innovator's dilemma: The revolutionary book that will change the way you do business. New York: Harper Business.

Hunter, M. (1994). Enhancing teaching. Upper Saddle River, NJ: Pearson Education.

Moore, M. (1997). Theory of transactional distance. In D. Keegan (Ed.), Theoretical principles of distance education (pp. 22-38). London: Routledge. Retrieved from: http://www.aged.tamu.edu/research/readings/Distance/1997MooreTransDistance.pdf

Moore, M. (1985). Some observations on current research in distance education. Epistolodidaktika, 1, 35-62.

Mortera-Gutiérrez, F. (2006). Faculty best practices using blended learning in e-learning and face-to-face instruction. International Journal on E-Learning, 5(3), 313-337.

O’Reilly, T. (2005). What is web 2.0? Design patterns and business models for the next generation of software. Retrieved from http://oreilly.com/web2/archive/what-is-web20.html.

Siemens, G. (2006). Knowing knowledge. Vancouver: Lulu Press. Retrieved from http://www.elearnspace.org/KnowingKnowledge LowRes.pdf.

Taylor, J. (1995). Distance education technologies: The fourth generation. Australian Journal of Educational Technology, 11(2), 1-7. Retrieved from http://www.ascilite.org.au/ajet/ajet11/taylor.html.

Taylor, J. (2001). Fifth generation distance education. e-Journal of Instructional Science \& Technology, 4(1), 1-14. Retrieved from http://eprints.usq.edu.au/136/.

Taylor, J. (2010). Sustainable higher education learning futures. Keynote address, AACE conference: Global Learn Asia Pacific, Penang. 


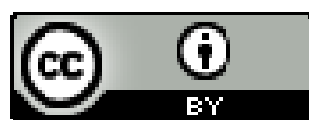

Athabasca University 